\title{
Prevalence and Factors Associated with Food Insecurity among Women Aged 18-49 Years in Kampala Slums Uganda; A Mixed Methods Study
}

\author{
Grace Nantale $^{1, *}$, Nazarius Mbona Tumwesigye ${ }^{2}$, Noah Kiwanuka ${ }^{2}$, Richard Kajjura ${ }^{1}$ \\ ${ }^{1}$ Department of Community Health and Behavioural Sciences, School of Public Health, \\ College of Health Sciences, Makerere University, Kampala, Uganda \\ ${ }^{2}$ Department of Epidemiology and Biostatistics, School of Public Health, College of Health Sciences, \\ Makerere University, Kampala, Uganda \\ *Corresponding author: gracenantale04@gmail.com
}

\begin{abstract}
While much focus has been put on rural household food insecurity, with increasing urbanisation leading to urban slum formation, food insecurity is potentially on the rise particularly among women of reproductive age (WRA). We determined the prevalence and factors associated with food insecurity among women aged 18-49 years in Makindye slums of Kampala capital city, Uganda. In a community based cross-sectional study, we recruited a random sample of 573 women aged 18-49 years, resident in the slums for at least one year prior to the study. Quantitative data were collected using interviewer administered questionnaires while qualitative information was obtained through key informant interviews and focus group discussions. Multivariable logistic regression (using STATA ${ }^{\circledR} 13$ ) and manifest content analysis methods were used to analyse quantitative and qualitative data respectively. Of the 573 participants, $60.7 \%$ were aged $20-34$ years, $53.7 \%$ were married/cohabiting, $12.2 \%$ had no formal education and $82.5 \%$ lived in rented homes. Overall $88.5 \%$ of the women were food insecure of which $68.4 \%$ were severely food insecure. Factors that increased likeli hood of food insecurity were; socioeconomic factors such as absence of electricity in the household (AOR; 2.2, 95\%CI: 1.05-4.86, $\mathrm{p}=0.036$ ) and having more than one school going child (AOR; 2.6, 95\%CI: 1.42-4.89, $\mathrm{p}=0.002$ ). Qualitative findings indicate that food insecurity is indeed a problem among women in the slums with unemployment, high food prices, poverty and increasing number of household members reported as the major causes of food insecurity. The prevalence of food insecurity among women in Kampala slums is high. These findings suggest the need to invest in economic empowerment of women with emphasis on those living in deprived communities.
\end{abstract}

Keywords: women of reproductive age, food insecurity, urban slums, Uganda, prevalence

Cite This Article: Grace Nantale, Nazarius Mbona Tumwesigye, Noah Kiwanuka, and Richard Kajjura, "Prevalence and Factors Associated with Food Insecurity among Women aged 18-49 years in Kampala Slums Uganda; A Mixed Methods Study.” Journal of Food Security, vol. 5, no. 4 (2017): 120-128. doi: 10.12691/jfs-5-4-2.

\section{Introduction}

Food security whether occurring at individual, household, national, regional and global levels is achieved when all people, at all times, have social, physical and economic access to safe, sufficient and nutritious food to meet their dietary needs and food preferences for a healthy and active life [1]. Food security at national and household levels does not automatically indicate food security at individual level due to a number of factors such as gender discrimination [2,3] with women being the most affected. In many societies women and girls eat the food remaining after the male family members have eaten, this "food discrimination" and unequal distribution of household food leaves most women with less quantity and less nutritive food [4,5], which makes them food insecure. Globally, it is estimated that $60 \%$ of the chronically hungry are women and girls due to their unequal access to education, employment and resources. Food insecurity among women of reproductive age (WRA) is a serious public health problem with adverse effects on the women, pregnancy outcomes and child survival; as well as on the economic development of the country ultimately negatively impacting the country's gross domestic product [6]. WRA who are food insecure are susceptible to poor health and nutritional status which reduces their economic productivity/employment opportunities [7], propagates the intergenerational cycle of malnutrition, leading to increased risk of maternal and child morbidity and mortality $[8,9]$ and poor cognitive and physical development among surviving children [10,11]. Studies indicate that food insecure women are more likely to suffer from poor nutritional, health and psychosocial consequences. The effects of food insecurity among women have been found to be a higher BMI and prevalence of obesity and overweight [12], maternal food insecurity has also been associated with loss of fat [13] leading to under nutrition and low BMI among women of reproductive age. The nutritional 
well being of women residing in slums is further compromised by the lack of access to safe water and sanitation, medical services and access to a diverse diet [14]. The sharp rise in food prices coupled with the economic downturn and its consequent increase in poverty, suggest that slum residents are experiencing a wide food gap. However, most efforts to address food insecurity are concentrating on rural areas with a glaring omission of urban dwellers [15]. With increasing urbanization and rapid expansion of urban slums, there is a need to determine the level of food insecurity among slum dwellers particularly WRA. While most of the previous studies on food insecurity used household as a unit of analysis, emerging evidence is pointing towards focusing on individual level food insecurity [16]. To address the aforementioned gaps, we conducted a study using individual level data, to determine the prevalence and factors associated with food insecurity among WRA residing in urban slums of Kampala city, Uganda.

\section{Methods}

\subsection{Study Setting}

The study was conducted in Makindye division slums, Kampala district. Makindye division is one of the 5 divisions in Kampala district with a population of 395,276 and women make up $52 \%$ of the total population in the division. It also has the most number of slums (ten) and the highest intra-population diversity within Kampala district [17].

\subsection{Study Participants}

For quantitative data, the primary respondents were women aged 18-49 years.

For qualitative data, the Local Council (L.C.) leaders and women representative leaders were identified for key informant interviews and women aged 18-49 years were also selected for focus group discussions.

\subsection{Sample Size and Sampling Design}

Using a design effect of 1.5 , precision of $5 \%$, a prevalence of $32.4 \%$ [18] and a non response rate of $10 \%$, the calculated sample size for quantitative data collection was 561 respondents.

\subsection{Sampling Procedure}

For quantitative data collection, multistage sampling involved selecting the sample in multiple steps. The sampling units were households and the study unit was women aged 18-49 years. Simple random sampling was used to select the parishes and zones (villages) using computer generated random numbers from each of the ten slums (ten clusters). Using a list of all households with WRA who had lived in the area for more than one year from each zone generated by the local council chairman, the households were sampled using probability proportional to size. One woman among others in the selected household who met the eligibility criteria was randomly sampled to participate in the study after consent. This procedure was continued until the desired number of respondents was obtained from each zone.

For qualitative data collection, a homogenous group of 12 women was purposively selected according to age to participate in the focus group discussions to allow free expression as much as possible. In the three randomly selected parishes, a total of six focus group discussions were conducted; with one for women aged 18-35years and the other for women aged more than 35 years in each parish, with each lasting for 75 minutes until saturation of information was achieved.

Purposively selected key informants including local council leaders, women representative leaders from each parish participated in the study. A total of six key informant interviews were conducted.

\subsection{Data Collection Tools}

A pretested interviewer-administered questionnaire was used for quantitative data collection. The research assistants who were final year undergraduate students in human nutrition of Kyambogo University were recruited trained and administered the questionnaires under the supervision of the principal investigator. The data collection tools were translated into Luganda, the local language spoken in the area.

A key informant guide and a focus group discussion guide were used to collect qualitative data.

Each focus group discussion lasted for 75 minutes at a convenient venue identified by the respondents. An interview guide was used to guide the discussion. All discussions were audio recorded in luganda and simultaneously translated into English language thereafter. A note taker recorded the points raised during the discussions and the meetings were moderated by the principle investigator. Key informant interviews (KIIs) were conducted by the principle investigator. The KIIs lasted nearly one hour and an interview guide was used to guide the interviews. All KIIs were audio recorded in luganda and transcribed into English thereafter.

\subsection{Measurement of Variables}

Prevalence of food insecurity was the dependent variable for the study.

The access component of food insecurity was assessed by using the experience/subjective based indicator using a standardized validated tool; the Individual Food Insecurity Access Scale, IFIAS). A study conducted in Uganda by Natamba et al, (2014) to assess the reliability and validity of the Individual Food Insecurity Access Scale (IFIAS) as a tool to assess food insecurity noted that it is a strong and appropriate measure of food insecurity that is relevant to the Ugandan context [19]. The questions covered 3 domains of food insecurity experience including anxiety and uncertainty about their food supply, insufficient quality, and insufficient quantity. The questions in the IFIAS were asked with a recall period of 30 days (4 weeks). The respondent was first asked an occurrence question, that is whether the condition in the question happened at all in the past four weeks (with the provision of 'yes' or 'no' response). If the respondent answered 'yes' to an occurrence question, a frequency-of-occurrence question 
was asked to determine whether the condition happened rarely (once or twice), sometimes (three to 10 times), or often (more than 10 times) in the past 4 weeks.

The individuals were finally categorized into four levels: 1) Food secure- when the individual 'rarely', in the past four weeks, worried about not having enough food and had replied 'no' to question number 2 to 9. 2) Mildly food insecure-- the individual worried about not having enough food sometimes or often, and/or were unable to eat preferred foods, and/or ate a more monotonous diet than desired, and/or ate some foods considered undesirable but only rarely. 3) Moderately food insecure- the individual sacrificed quality more frequently by eating a monotonous diet or undesirable foods sometimes or often, and/or had started to cut back on quantity by reducing the size of meals or number of meals, rarely or sometimes. 4) Severely food insecure-individual had to cut back on meal-size or number of meals often, and/or experienced any of the three most severe conditions (running out of food, going to bed hungry, or going a whole day and night without eating).

To assess individual dietary quality, the dietary diversity scores for women were obtained. Using a standard dietary diversity score questionnaire; a standardized questionnaire for measuring dietary diversity has been revised with a number of new changes like categorizing individual food items into food group [20]. This involved asking the respondents to list all foods consumed at home and out of home in the previous 24 hours preceding the interview. The respondents were asked to recall all the foods eaten, snacks and beverages taken in the previous 24 hours prior to the interview, however if the previous 24 hour was atypical due to special occasion, a different day was selected for the interview. A detailed description of food eaten was collected and for mixed dishes, the food items were disaggregated and categorised into appropriate food groups. Food and Agriculture Organisation (FAO) recommends and uses a reference period of the previous 24 hours as it is less cumbersome for the respondent and less subject to recall bias [20]. All the food items consumed by the respondents were categorized into 9 food groups namely; starchy staples, fruits, vegetables, milk and dairy products, vitamin A rich foods, legumes, meat/fish/organ meat/poultry, eggs, fats/oils and beverages. The 9 food groups were based on the local and international food grouping techniques adapting cultural context [21]. A single point was awarded to each of the food groups consumed by the individual giving a total score of 9 points for each individual given that all her responses were positive for all food groups. Mutually exclusive dietary diversity categories were derived from the 9 food groups into meeting dietary diversity if an individual score equals or is more than $5 / 9$ and not meeting dietary diversity if an individual scores less than or equal to $4 / 9$.

Independent variables included demographic and socio economic characteristics ( age, marital status, educational level, parity, household composition, number of school going children, employment status, monthly income, household utility bills, monthly expenditure on food items).

\subsection{Data analysis}

Quantitative data was entered into Epidata and transferred to STATA version 13 for statistical analysis.
Descriptive analysis; the categorical variables were summarized and presented as proportions which are presented in tables, charts and bar graphs. Bivariate analysis; logistic regression was used to detect associations between independent variables and dependent variable. The strength of association between the independent variables (covariates) and the dependent variable was expressed using crude odds ratios at a significant level of 0.05 . Multivariate analysis was done to determine the factors associated with food insecurity. The final logistic model was adjusted for the following variables; which had a statistically significant bivariate relationship with food insecurity: educational level, age groups, parity, number of school going children, paying for electricity and marital status. The measure of association is odds ratio (OR) with precision measured using 95\%confidence interval around the OR and p-value was considered significant at $<0.05$.

Qualitative data analysis was done manually by coding the responses into themes and sub themes. Manifest content analysis was used to come up with emerging themes; some of the reported statements were quoted verbatim to give exact meaning.

\subsection{Ethical Consideration}

The study was approved by the Makerere University Higher Degrees Research Ethics Committee. Voluntary informed written consent was obtained from each respondent before questionnaire administration, privacy and confidentiality was observed and respondents were not required to write any information identifying them to ensure anonymity. Voluntary informed verbal consent was obtained from the respondents before qualitative data collection.

\section{Results}

\subsection{Socio Demographic Factors}

The results indicated that the mean age was $30( \pm 8)$ years and the median age was 34(18-49) years. More than two thirds (70\%) of the respondents were aged 20-34 years and less than 20 years. About a half (49.4\%) of the respondents had attained primary or less educational level. Nearly a half (47.5\%) of the respondents had more than one school going child. More than half (64.6\%) of the respondents had a total of 4 or more household members as shown in Table 1.

The results further indicated that about two thirds (59.3\%) of the respondents were unemployed. Most of the respondents (85.2\%) had a monthly income equal to or less than 41 US dollars. Nearly a quarter (26.4\%) of the respondents did not have electricity in their households. About three quarters (71.8\%) of the respondents spent more than 41 US dollars a month on food items as Table 2.

\subsection{Prevalence of Food Insecurity}

Table 3 shows that in the past 30 days, most of the women (57.2\%) were 'sometimes' uncertain and worried about not having enough food, 30.9\% were ' often' and 
$11.9 \%$ were 'rarely' uncertain and worried about not having enough food. The results indicate that $58.9 \%$ of the women 'sometimes' had to eat a limited variety of foods, $25.9 \%$ 'often' and $15.1 \%$ 'rarely' had to eat a limited variety of foods due to a lack of resources such as money. About $60.2 \%$ of the women 'sometimes' had to eat a smaller meal than they felt they needed because there was not enough food, $27.6 \%$ 'often' and $12.2 \%$ of the women 'rarely' had to eat a smaller meal than they felt they needed because there was not enough food.

Table 1. Demographic characteristics of women aged 18-49 years in Makindye division slums

\begin{tabular}{|c|c|c|c|}
\hline Variable & Category & $\mathbf{n}$ & Percent \\
\hline \multirow[t]{2}{*}{ Gender of household head } & Male & 323 & 56.4 \\
\hline & Female & 250 & 43.6 \\
\hline \multicolumn{4}{|l|}{ Age (years) } \\
\hline & $18-19$ & 53 & 9.3 \\
\hline & $20-34$ & 348 & 60.7 \\
\hline & $35-49$ & 172 & 30.0 \\
\hline \multicolumn{4}{|l|}{ Marital status } \\
\hline & Married & 114 & 19.9 \\
\hline & Cohabiting & 194 & 33.9 \\
\hline & Single & 144 & 25.1 \\
\hline & Divorced & 77 & 13.4 \\
\hline \multicolumn{4}{|l|}{ Educational level } \\
\hline & Widowed & 44 & 7.7 \\
\hline & Tertiary & 37 & 6.5 \\
\hline & Secondary & 253 & 44.2 \\
\hline & Primary & 213 & 37.2 \\
\hline & None & 70 & 12.2 \\
\hline \multicolumn{4}{|l|}{ Religion } \\
\hline & Protestant & 159 & 27.7 \\
\hline & Catholic & 203 & 35.4 \\
\hline & Muslim & 103 & 18.0 \\
\hline & Born again & 95 & 16.6 \\
\hline & Others & 13 & 2.3 \\
\hline \multicolumn{4}{|l|}{ Tenure } \\
\hline & Own & 100 & 17.5 \\
\hline & Rented & 473 & 82.5 \\
\hline \multicolumn{4}{|l|}{ Parity } \\
\hline & $\leq 4$ children & 457 & 79.8 \\
\hline & $>4$ children & 116 & 20.2 \\
\hline \multicolumn{4}{|l|}{ Number of school going children } \\
\hline & $\leq 1$ & 301 & 52.5 \\
\hline & $>1$ & 272 & 47.5 \\
\hline \multicolumn{4}{|l|}{ Number of household members } \\
\hline & $\leq 3$ & 203 & 35.4 \\
\hline & $4-5$ & 188 & 32.8 \\
\hline & $>5$ & 182 & 31.8 \\
\hline
\end{tabular}

Table 2. Socio-economic characteristics of women aged 18-49 years in Makindye division slums

\begin{tabular}{|l|l|l|l|}
\hline Variable & Category & $\mathrm{n}$ & Percent \\
\hline Occupational status & Employed & 233 & 40.7 \\
Monthly income & $\leq \$ 41$ & 340 & 59.3 \\
& $>\$ 41$ & 488 & 85.2 \\
Paid for water & & 85 & 14.8 \\
& Yes & & \\
Availability of electricity in the & No & 534 & 93.2 \\
household & & 39 & 6.8 \\
& Yes & & \\
Own a phone & No & 422 & 73.6 \\
& & 151 & 26.4 \\
Monthly expenditure on food & Yes & 424 & 74.0 \\
& No & 149 & 26.0 \\
& $>$ or $=\$ 41$ & 93 & 28.2 \\
& $>41$ & 41.8 \\
\hline
\end{tabular}

The results in Figure 1 indicate that most of the respondents $(88.5 \%)$ were food insecure with about two thirds (68.4\%) being severely food insecure.

The results in Table 4 indicate that of those WRA that were food insecure, slightly more than a quarter (27.7\%) were aged $35-49$ years. A half (53.2\%) of the women were aged 20-34 years and less than a tenth $(7.5 \%)$ of the women participants aged less than 20 years were food insecure. Most of the respondents had consumed the following food groups in the previous 24 hours to the interview; starchy staples (99.3\%), beans, peas, groundnuts $(70.2 \%)$ and $82.9 \%$ had consumed fats and oils. The least consumed food groups were fruits (34.7\%), vegetables (35.8\%), vitamin A rich foods (0.7\%), eggs (5.1\%), milk and dairy products (10.5\%), meat, fish, organ meat and poultry (44.2\%).

\subsection{Factors Associated with Food Insecurity}

Table 5 shows that at bivariate analysis; being aged 2049 years, educational level of secondary or less, parity of more than 4 , having more than 1 school going child and having 4 or more household members were statistically significant for food insecurity. Marital status, gender of household head and household tenure were not statistically significant.

Illiterate respondents were 4.4 times more likely to be food insecure than those who had attained a tertiary level of education.

Respondents aged 35-49 years were 2.8 times of being food insecure more than respondents aged less than 20 years.

Respondents with a parity of more than 4 were 2.3 times more likely to be food insecure than those with a parity of less or equal to 4 . 
Table 3. Prevalence of food insecurity, based on Individual Food Insecurity Access Scale, among women aged 18-49 years in urban slums in Makindye division Kampala

\begin{tabular}{|c|c|c|c|c|}
\hline Question & $\begin{array}{c}\text { Yes } \\
\text { n (\%) }\end{array}$ & $\begin{array}{l}\text { Rarely } \\
\text { n (\%) }\end{array}$ & $\begin{array}{l}\text { Sometimes } \\
\text { n (\%) }\end{array}$ & $\begin{array}{l}\text { Often } \\
\text { n (\%) }\end{array}$ \\
\hline $\begin{array}{l}\text { 1. In the last four weeks, did you worry that you would not } \\
\text { have enough food? }\end{array}$ & 395 (68.94) & 47 (11.90) & $226(57.22)$ & 122 (30.89) \\
\hline $\begin{array}{l}\text { 2. In the past four weeks, were you not able to eat the kinds of } \\
\text { foods you preferred because of a lack of resources such as } \\
\text { money? }\end{array}$ & 449 (78.36) & $66(14.70)$ & $270(60.13)$ & 113 (25.17) \\
\hline $\begin{array}{l}\text { 3. In the past four weeks, did you have to eat a limited variety } \\
\text { of foods due to a lack of resources such as money? }\end{array}$ & 358 (62.48) & 54 (15.08) & 211 (58.94) & 93 (25.98) \\
\hline $\begin{array}{l}\text { 4. In the past four weeks, did you have to eat some foods that } \\
\text { you really did not want to eat because of a lack of resources to } \\
\text { obtain other types of food? }\end{array}$ & 455 (79.41) & 69 (15.16) & $296(65.05)$ & 90 (19.78) \\
\hline $\begin{array}{l}\text { 5. In the past four weeks, did you have to eat a smaller meal } \\
\text { than you felt you needed because there was not enough food? }\end{array}$ & 337 (58.81) & 41 (12.17) & 203 (60.24) & 93 (27.60) \\
\hline $\begin{array}{l}\text { 6. In the past four weeks, did you have to eat fewer meals in a } \\
\text { day because there was not enough food? }\end{array}$ & 346 (60.38) & 45 (13.01) & $156(45.09)$ & 145 (41.91) \\
\hline $\begin{array}{l}\text { 7. In the past four weeks, was there ever no food to eat of any } \\
\text { kind because of lack of resources to get food? }\end{array}$ & 297 (51.83) & 54 (18.18) & $164(55.22)$ & 79 (26.60) \\
\hline $\begin{array}{l}\text { 8. In the past four weeks, did you go to sleep at night hungry } \\
\text { because there was not enough food? }\end{array}$ & 237 (41.36) & 43 (18.14) & $126(53.16)$ & 68 (28.69) \\
\hline $\begin{array}{l}\text { 9. In the past four weeks, did you go a whole day and night } \\
\text { without eating anything because there was not enough food? }\end{array}$ & 75 (13.09) & 25 (33.33) & 40 (53.33) & 10 (13.33) \\
\hline
\end{tabular}

\section{Severe Food insecurity}

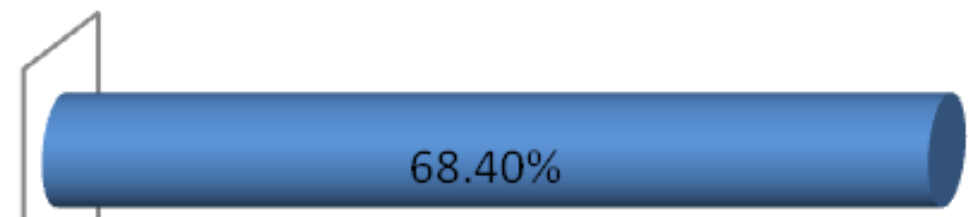

Moderate Food insecurity

Mild Food insecurity

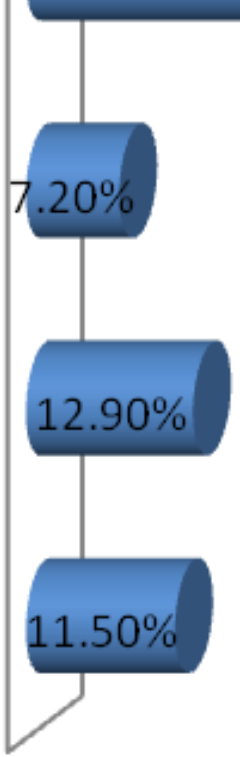

Figure 1. Prevalence and severity of Food Insecurity among women aged 18-49 years in Makindye division slums

Table 4. Distribution of food insecurity by age of women aged 18-49 years in Makindye division slums

\begin{tabular}{|l|c|c|c|c|}
\hline & $\begin{array}{c}<20 \text { years } \\
\mathbf{n ~ ( \% )}\end{array}$ & $\begin{array}{c}\text { 20-34years } \\
\mathbf{n ~ ( \% )}\end{array}$ & $\begin{array}{c}\text { 35-49 years } \\
\mathbf{n}(\mathbf{\%})\end{array}$ & $\begin{array}{c}\text { Total } \\
\mathbf{n}(\%)\end{array}$ \\
\hline Food Secure & $10(1.7 \%)$ & $43(7.5 \%)$ & $13(2.3 \%)$ & $66(11.5 \%)$ \\
\hline Food Insecure & $43(7.5 \%)$ & $305(53.2 \%)$ & $159(27.7 \%)$ & $507(88.4 \%)$ \\
\hline Total & $53(9.2 \%)$ & $348(60.7 \%)$ & $172(30.0 \%)$ & $573(99.9 \%)$ \\
\hline
\end{tabular}


Table 5. Factors associated with food insecurity among women aged 18-49 years in Makindye division slums

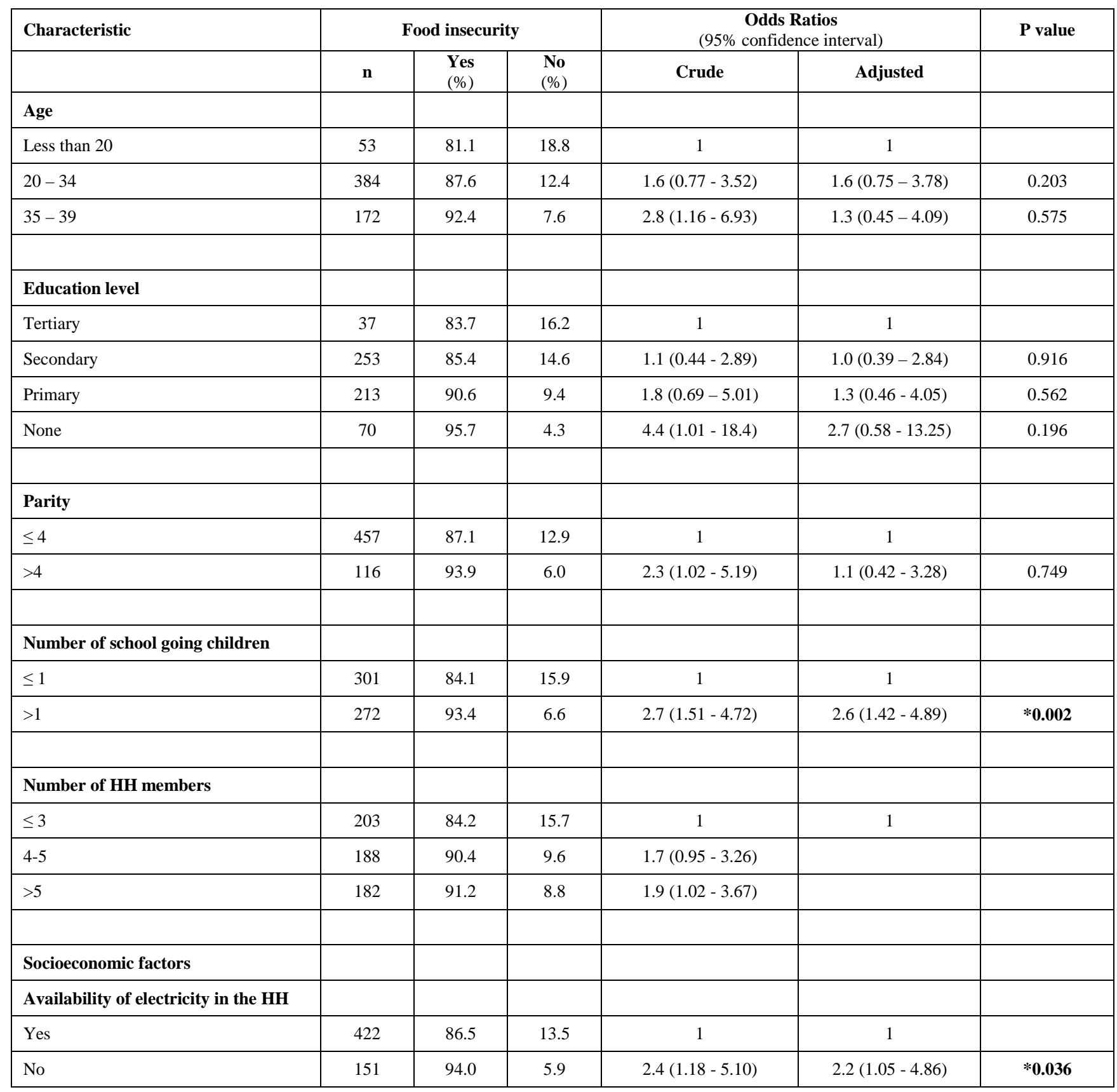

${ }^{*}$ p- values are for multivariate analysis *statistically significant $\mathbf{P}<\mathbf{0 . 0 5}$.

Having more than one school going child predicted 2.7 times more of being food insecure than those who had one or no school going child (OR; 2.7 95\%CI: 1.51-4.72).

Having more than 5 household members increased the likelihood of being food insecure than those who had 3 or less household members (OR; 1.90).

Individuals who did not have electricity in the household were 2.4 times more likely to be food insecure than those who had electricity in the household.

Multivariate analysis using logistic regression revealed that having more than one school going child and not having electricity in the household were significantly associated with food insecurity, in a model that also included educational level, age groups, parity and marital status.

Respondents who reported not having electricity in the household were 2.2 times more likely to be food insecure than those who had electricity (OR; 2.20 95\%CI: 1.05- 4.86, $\mathrm{p}=0.036)$.

Respondents with more than 1 school going child were more likely to be food insecure than those who had one or no school going child (OR; 2.60 95\%CI: 1.42- 4.89, $\mathrm{p}=0.002)$ as shown in Table 5 .

\subsection{Qualitative Findings}

A total of six key informant interviews and six FGD sessions were conducted. The respondents gave their views on their perception towards food insecurity which were classified into 8 major themes. The themes were; understanding of food insecurity, magnitude of food insecurity, signs, causes, consequences of food insecurity, number of meals and foods commonly consumed and recommendations. 


\subsubsection{Perceptions on Understanding of Food Insecurity}

Results from five out of six KIIs and all the six FGDs indicated that the participants perceived food insecurity as lack of money. It was also noted that food availability within these slums was constant however the woman's ability to access this food largely depended on their financial ability.

"It means that she does not have money" (FGD- women -kisugu)

\subsubsection{Perception on the Causes of Food Insecurity}

Results from the interviews and discussions revealed that some of the major causes of food insecurity were unemployment, domestic violence, high food prices and increasing number of household members.

Results from all the six KIIs and the six FGDs further revealed that unemployment was the major cause of food insecurity and it was attributed to lack of capital to enable women get involved in small businesses that would allow them to be financially independent thus being food secure. Low educational level was also cited in that even the casual employment needed at least some information on how to manage their businesses which most of them lacked.

"Not working, most of us do not work that is the most important factor, the education level may be so low that they ask for qualifications that you do not have [in other words they ask for a qualification which you may not have]" (FGD women- Kisugu).

Domestic violence was also reported as one of the causes of food insecurity and as a result of this, men neglect their responsibility of providing food for the family and this greatly affects the woman as an individual.

"but when ever these people have a miss understanding and bring cases to the LC there will be no eating of food you find a man when he has said that to hell with you, you can stay without food" (KII kikubamutwe).

High food prices were also identified as a cause of food insecurity. This coupled with the high standard of living in the city makes the women unable to access sufficient, nutritious foods.

"In our area here we have so many problems but it is all about money. you have got your little money but the land lord is sited there waiting for it, sickness is also looking at you, food is demanding even the toilet we pay for it ,water everything we pay for it everything is to be solved by the little money that we have"(FGD womenNamuwongo).

\subsubsection{Number of Meals and Type of Food Commonly Consumed}

Results from five out of six KIIs and all FGDs revealed that most women had one -two meals a day and the most consumed foods were posho and beans.

"The common food consumed by women here is posho because it is not very expensive and most of them also eat millet and cassava flour but at times even these scarce” (FGD women- kisugu).

"I know that people here eat once and there are those who don't even get that one meal they take porridge for the whole day. It is very hard to get a person who gets two meals, and what causes them to have one meal is the situation. Others take porridge even at times they fail to get the porridge and you see them going to neighbors at times they come here” (KII -Namuwongo).

\subsubsection{Perception on Consequences of Food Insecurity}

Results from all the six KIIs and all the six FGDs identified some of the consequences of food insecurity as affecting the health of the woman and her psychological well being. The health related effects mentioned were diseases such as ulcers, hypertension and poor psychological wellbeing that included stress, worry and depression. The results also indicated that women were at risk of being involved in risky social behaviours that would put their lives at risk such as prostitution that would expose them to HIV/AIDS ,and substance abuse especially alcohol abuse due to stress of being food insecure.

"To know that it is a problem is when our children are getting sick because when our children do not have nutritious food they fall sick [even us women we fall sick a lot” (FGD -Women Kisugu).

"Also if this woman is to conceive she gets problems because even the unborn baby is demanding. You find in the end this woman may find problems while delivering and even the child may be born immature” (KII-Nsambya central).

\subsubsection{Perception on Solutions to Food Insecurity}

Recommendations were made towards solving food insecurity among this population. Results from all six KIIs and all the FGDs identified skills training with support from NGOs and government bodies that are responsible for the well being of these women so that they can be empowered to start small businesses that can be a source of income thus enabling them to have access to safe, sufficient and nutritious foods.

"If they were people who can come to the community and bring skills training workshops and train women in basket weaving, so that they can be self employed and also get them market where they can sell them. I think the situation can change since they are supported with businesses that are brought into the community with an aim of improving the quality of life of low status woman" (KII - Kisugu).

\section{Discussion}

This cross sectional study set out to determine the prevalence and factors associated with food insecurity among women aged 18-49 years in makindye slums Kampala. In this study the prevalence of food insecurity was $88.5 \%$ with $68.4 \%$ of these women experiencing severe food insecurity. The high level of food insecurity could be a major factor contributing to the high rates of under nutrition among women of reproductive age. This study finding is consistent with findings from a study conducted in an urban colony of North India by Chinnakali (2014) to determine the prevalence of household food insecurity. The study also reported a high (77.2\%) prevalence of food insecurity [22]. The consistence in the findings could be due to similar study settings in urban slums. 
This is supported by results from KIIs and FGDs which revealed that a high number of women in the study area were financially unable to access food due to unemployment and therefore experienced food insecurity.

The study found that the quality of food consumed was not meeting the recommended dietary diversity score with increased intake of starchy staples, pulses and reduced intake of fruits, vegetables, and meat, fish and poultry products. This finding is similar to that reported by Bawadi H et al,(2012) and Gulliford MC et al, (2003) which noted that food insecure individuals were more likely to consume less nutritious, monotonous starchy staples $[18,23]$. This is also supported by results from the FGDs during which respondents reported increased consumption of cheap starchy staples (posho, millet, cassava flour) and pulses.

In this study, illiterate women were more likely to be food insecure. These findings are consistent with previous studies which reported that illiteracy among women was associated with food insecurity [18,24,25]. This result is supported by findings from the FGDs which noted that some of them cannot be employed because of low educational levels.

The low educational levels lead to unemployment among women as noted in the UBOS (2014) report that the proportion of unemployed women in urban areas is higher than that in rural areas [26]. This results in women with lower educational levels to be housewives or to engage in informal risky economic activities without a steady income leaving them with insufficient purchasing power to access safe, nutritious and sufficient foods. Low education among women coupled with few economic opportunities hinders the women's ability to access foods in a socially acceptable way resulting in risky coping strategies.

The present study also found that women with more than one school going child were more likely to be food insecure than those with one or no school going children. This finding is consistent with findings from a study done in Malaysia which noted that food insecure women had an increased number of children [25]. School going children tend to increase the household expenses due to school related fees. This coupled with low earning potential tends to worsen food insecurity among women. This means that the school going child will always be undernourished and unable to concentrate in class leading to constant absenteeism. This may result into the intergenerational transmission of food insecurity and poverty when children are withdrawn from school because of school fees becoming unaffordable.

The FGDs revealed that increasing number of household members was one of the demographic characteristics leading to food insecurity among these women. This finding is consistent with other studies which reported that household composition and family type have been found to be attributed to food insecurity among low-income urban household $[27,28]$. The high number of household members tends to lead to increased expenditure on food. However with low income levels, the household expenditure on food is significantly reduced. As a result, the women end up consuming insufficient, less nutritive foods leaving them food insecure and prone to under nutrition.

In this study, women who did not have electricity in their households were more likely to be food insecure than those who had electricity in the household. The respondents who did not have electricity in their households were unable to pay for it; this is an indirect indication of low income levels and low earning potential which in turn affects the women's ability to access food. The other socioeconomic variable that was associated with food insecurity was monthly expenditure on food. This can also be due to income levels where women with low income levels are more likely to spend less on food items hence leaving them food insecure as reported in previous studies by $[18,29,30]$.

FGDs and KIIs indicated that unemployment and high food prices were the main causes of food insecurity among women in slums. This was attributed to low income levels, high standard of living and high prices of food. This finding is consistent with another study by Brown (2014) which indicated that food prices are increasing leaving many urban residents unable to access food [14]. This is also similar to findings from another study by Crush (2010) which noted that slum dwellers are usually faced with high costs of living which undermines their ability to access sufficient, safe and nutritious foods [31]. Access to food among urban residents entirely depends on one's purchasing power. Macroeconomic factors such as low wages, high housing costs, high unemployment rates and high tax burdens increase the probability of food insecurity in women. When income is constrained or limited, women may be forced to make decisions that can result in a less than adequate supply of food.

\section{Study Limitations}

Recall bias was likely to occur among some respondents during the face to face interview since information on a number of variables was self reported(including those related to the outcomes and predictor) which can result in measurement errors that introduced bias. In addition a single 24 hour dietary recall may provide a less precise measure of the respondents' usual intake.

\section{Conclusion}

This study found a high prevalence of food insecurity among women aged 18-49 years in an urban slum. Increased household expenditures such as having more than one school going child coupled with low earning were associated with food insecurity. In order to reduce the proportion of food insecure WRA and the effects of food insecurity on maternal child health, there is need to set up economic empowerment programs for women in slums. As well as other studies are needed to create sufficient evidence to influence urban policy makers so that appropriate interventions against food insecurity among WRA in urban slums are set up.

\section{Acknowledgements}

The research team is grateful to the Makerere University Centre of Excellence for Maternal and Newborn Health 
Research (CMNHR) for the financial support towards the study. The support offered by the coordinators of this grant program at Makerere University School of Public Health is acknowledged. Special gratitude goes to the makindye community including the local leaders and women who participated in this study. Our appreciation goes to the data collectors and supervisors.

\section{Statement of Competing Interests}

The authors have no competing interests.

\section{Abbreviations}

WRA- Women of Reproductive Age

BMI - Body Mass Index

IFIAS-Individual Food Insecurity Access Scale

FAO - Food and Agriculture Organisation

DDS- Dietary Diversity Score

OR-Odds Ratios

\section{References}

[1] Food and Agriculture Organisation. "Rome Declaration on Food Security and World Food Summit Plan of Action." Rome 1996.

[2] Miller, BD. Social class, gender and intrahousehold food allocations to children in South Asia. Soc Sci Med. 1997; 44: 1685-95

[3] Haddad LJ, Peña C, Nishida C, Quisumbing AR,Slack AT. Food security and nutrition implications of intrahousehold bias: a review of literature. Washington D. C : International Food Policy Research Institute,(FCND discussion paper no. 19) 1996.

[4] Mukherjee, A. Food insecurities faced by women and girl children. CAPSA-ESCAP. Bogor 2010; 11 (Occassional CAPSA paper no 2).

[5] Karl, M. "Inseparable: The Crucial Role of Women in Food Security Revisited. Women in Action." 2009.

[6] WFP. Fighting Hunger Worldwide. Rome 2015. http://www.wfp.org/search/site/gdp.

[7] Austin OC, Nwosu AC, Baharuddin AH. Rising food insecurity: dimensions in farm households. Am J Agric Biol Sci 2011; 6: 403-9.

[8] Ramakrishnan, U. Nutrition and low birth weight: from research to practice. Am J Clin Nutr 2004: 79: 17-21.

[9] Laraia BA., Seiga-Riz AM., Gundersen C. "Household food insecurity is associated with self-reported pregravid weight status, gestational weight gain, and pregnancy complications". Journal of American Dietitics Association 2010; 110: 692-701.

[10] Alderman H, Hoddinott J, Kinsey B,. Long term consequences of childhood malnutrition. Oxf Econ Paper 2006; 58: 450-74.

[11] Liu J, Raine A The effect of childhood malnutritionon externalizing behavior. Curr Opin Pediatr 2006;18: 565-70.

[12] Hromi-Fiedler A, Bermudez-Millan A., Segura-Pérez S, PerezEscamilla R. "Household food insecurity is associated with depressive symptoms among low-income pregnant Latinas." Maternal Child Nutrition 2011; 7: 421-30.

[13] Widen M Elizabeth, Collins M Shalean, Khan Hijab, Biribawa Claire, Acidri Daniel, Achoko Winifred, Achola Harriet, Ghosh
Shibani, Griffiths K Jeffrey and Young L Sera.Food insecurity, but not HIV-infection status, is associated with adverse changes in body composition during lactation in Ugandan women of mixed HIV status. American Journal of Clinical Nutrition 2017; 10: 116142513.

[14] Brown, Andrea M. "Uganda's Emerging Urban Policy Environment:Implications for Urban Food Security and Urban migrants." Urban Forum 2014; 25: 253-264.

[15] United Nations, Department of Economics and Social Affairs, Population Division. World Urbanisation Prospects: The 2014 Revision, Highlights (ST/ESA/SER.A/352). The United Nations 2014.

[16] Coates J., Webb P., Houser Robert F., Wilde Parke. "He said she said": Who should speak for households about experiences of food insecurity in Bangladesh. Food Security Journal 2010; 2: 81-95.

[17] Uganda Bureau of Standards (UBOS). National Population and Housing Census. Provisional Results. 2014.

[18] Bawadi Hiba A., Tayyem Reema F., Dwairy Amal N.and AlAkour Nemeh. "Prevalence of Food Insecurity among Women in Northern Jordan." Journal of Health Population Nutrition 2012; 30: 49-55.

[19] Natamba Barnabas K, Kilama H., Angela Arbach, Jane Achan, Jeffrey K Griffiths and Sera L Young. "Reliability and validity of an individually focused food insecurity access scale for assessing inadequate access to food among pregnant Ugandan women of mixed HIV status." Public Health Nutrition 2015; 18: 2895-905.

[20] FAO. Guidelines for measuring household and individual dietary diversity. Rome, Italy.: Food and Agriculture Organisation of the United Nations, 2011.

[21] Swindale, Anne, and Paula Bilinsky. Household Dietary Diversity Score (HDDS) for Measurement of Household Food Access: Indicator Guide (v.2). Washington, DC: FHI 360/ FANTA., 2006. 20009-5721.

[22] Chinnakali P., Ravi P. Upadhyay, Deepa Shokeen, Kavita Singh, Manpreet Kaur, Arvind K. Singh, Anil Goswami, Kapil Yadav, Chandrakant S. Pandav.Prevalence of Household-level Food Insecurity and Its Determinants in an Urban Resettlement Colony in North India. Journal of Health Population Nutrition 2014; 32: 227-236.

[23] Gulliford MC, Mahabir D, Rocke B. Food insecurity,food choices, and body mass index in adults: nutrition transition in Trinidad and Tobaga. International Journal of Epidemiology 2003; 32:508-16.

[24] Rahman Azizur and Rezaul, Karim. Prevalence of Food Insecurity among women in Rural Area of North West Bangladesh. Pakistan Journal of Nutrition 2013; 12: 329-333.

[25] Shariff ZM, Khor GL. Obesity and household food insecurity: Evidence from a sample of rural households in Malaysia. European Journal of Clinical Nutrition 2005; 59:1049-58.

[26] Uganda Bureau of Standards(UBOS). Statistical abstract. Kampala, Uganda 2014

[27] Maitra Chandana and D.S.Prasada, Rao. C Poverty-Food Security Nexus: Evidence from a Survey of Urban Slum Dwellers in Kolkata. Elsevier World Development 2015; 72: 308-325.

[28] Ramsey Rebecca, Giskes Katrina, Turrell Gavin and Gallegos Danielle.Food Insecurity among adults residing in disadvantaged urban areas. Potential health and dietary consequences. Public Health Nutrition 2012; 15: 227-37.

[29] Laraia, Barbara A. Food Insecurity and Chronic Diseases. Advances in Nutrition 2013; 4: 203-212.

[30] Laraia BA, Siega-Riz AM, Gundersen C, Dole N. Psychological factors and socioeconomic indicators are associated with household food insecurity among pregnant women. Journal of Nutrition 2006; 136: 177-182.

[31] Crush, Jonathan and Bruce Frayne. "The Invisible Crisis: Urban Food Security in Southern Africa." Cape Town and Kingston. Urban Food Security Series No.1 Queen's University and AFSUN 2010. 